\title{
Isolation of DNA sequences on human chromosome 21 by application of a recombination-based assay to DNA from flow-sorted chromosomes
}

\author{
Umadevi Tantravahi ${ }^{1,3}$, Gordon D.Stewart ${ }^{6}$, Margaret Van Keuren $^{6}$, Gerard McNeil ${ }^{1,3}$, Sayon Roy ${ }^{1,3}$, David Patterson $^{5}$, \\ Harry Drabkin ${ }^{5}$, Marc Lalande ${ }^{1,3}$, David M.Kurnit ${ }^{6}$, and Samuel A.Latt ${ }^{1,2,3,4}$ \\ ${ }^{1}$ Genetics Division and Mental Retardation Center, The Children's Hospital, ${ }^{2}$ Howard Hughes Medical Institute at The Children's Hospital, \\ ${ }^{3}$ Department of Pediatrics and ${ }^{4}$ Department of Genetics, Harvard Medical School, Boston, MA 02115, USA \\ ${ }^{5}$ Eleanor Roosevelt Institute for Cancer Research, University of Colorado Health Sciences Center, Denver, CO' 80206, USA \\ ${ }^{6}$ Howard Hughes Medical Institute at the University of Michigan Medical Center, Ann Arbor, MI 48109, USA
}

\begin{abstract}
Summary. By merging two efficient technologies, bivariate flow sorting of human metaphase chromosomes and a recombination-based assay for sequence complexity, we isolated 28 cloned DNA segments homologous to loci on human chromosome 21. Subregional mapping of these DNA segments with a somatic cell hybrid panel showed that 26 of the 28 cloned DNA sequences are distributed along the long arm of chromosome 21 , while the other 2 hybridize with sequences on the short arm of both chromosome 21 and other chromosomes. This new collection of probes homologous to chromosome 21 should facilitate molecular analyses of trisomy 21 by providing DNA probes for the linkage map of chromosome 21, for studies of nondisjunction, for chromosome walking in clinically relevant subregions of chromosome 21 , and for the isolation of genes on chromosome 21 following the screening of cDNA libraries.
\end{abstract}

\section{Introduction}

Chromosome-specific DNA sequences are isolated most readily from preparations carrying a restricted portion of the human genome. This was originally accomplished using somatic cell hybrids that retained a single human chromosome (Gusella et al. 1980). More recently, it has been possible to enrich for individual metaphase chromosomes by fluorescence-activated flow sorting (Davies et al. 1981; Kunkel et al. 1983; Young 1984). The advent of bivariate flow cytometric analysis (Gray et al. 1979; Langlois et al. 1982; Lebo et al. 1984; Collard et al. 1985; Donlon et al. 1986; Muller et al. 1986) has made this latter method especially powerful, as it is now feasible to distinguish most human chromosomes. Specifically, the use of two dyes, between which the transfer of energy enhances differences in fluorescence according to clustering of A-T or G-C base pairs (Sahar and Latt 1978; Van Dilla et al. 1986), improves the resolution of chromosome 21 from other small chromosomes, thereby permitting the isolation of preparations highly enriched for chromosome 21.

DNA from hybrids that retain the chromosomes of interest or from flow-sorted chromosomes is isolated and cloned,

Offprint requests to: S. A. Latt, Genetics Division, The Children's Hospital, 300 Longwood Avenue, Boston, MA 02115, USA creating human chromosome-enriched libraries (for reviews see Young 1984; Van Dilla et al. 1986 and Latt et al. 1985). Isolation of nonrepetitive chromosome-specific human DNA sequences from these libraries, which is typically the next step, involves repeated screening of individual phage inserts for homology with radiolabeled total human genomic DNA. Screening of individual DNA segments with radiolabeled total human genomic DNA (Gusella et al. 1980) will identify those cloned segments present 100 or more times in the genome (Kurnit et al. 1982). From the remaining clones or subclones, those that contain human DNA but are free of chromosomeunspecific repeat sequences can then be conveniently mapped to chromosomes and then to subchromosomal regions, e.g., by using appropriate panels of DNA from somatic cell hybrids.

A major flaw with the above procedure is that clones lacking recombinant DNA inserts or containing DNA inserts that are moderately repetitive (10-100 copies per genome) are not initially distinguished from the desired few-copy (1-10 copies per genome) DNA sequences. To circumvent these technical problems, we applied a recombination-based assay (Neve and Kurnit 1983) that distinguishes clones carrying highly repetitive, moderately repetitive, or no human DNA insert from those carrying few-copy DNA inserts.

Here we studied flow-sorted chromosome 21-enriched DNA segments that were inserted into a miniplasmid, piAN7 (Huang et al. 1986), designed for the recombination-based assay. Using this assay, 49 nonrepetitive miniplasmid inserts were isolated and mapped using Southern blotting techniques (Southern 1975). Of these inserts 28 exhibited homology with DNA from chromosome 21. Each of these inserts was then mapped subregionally on chromosome 21 using a somatic cell mapping panel designed for this purpose (Van Keuren et al. 1986). We thereby obtained an array of molecular probes that can serve as anchor points for characterizing more fully the molecular organization of human chromosome 21 .

\section{Materials and methods}

Construction of a human chromosome 21-enriched recombinant DNA library in the miniplasmid piAN7

PiAN7 (gift of H.Huang) is an 885-bp (base pair) plasmid consisting of a ColE1 replicon, a supF gene, and a polylinker 


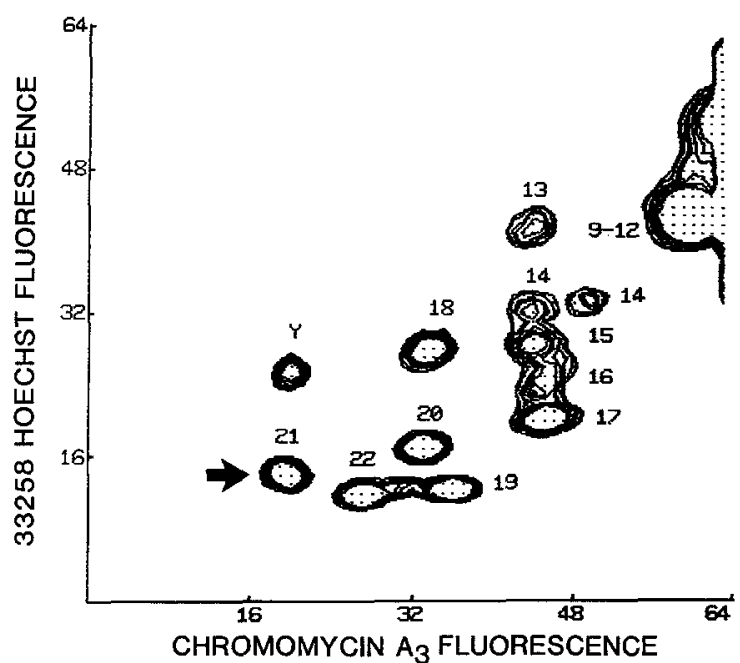

Fig. 1. Resolution of chromosome 21 by bivariate flow sorting. Metaphase chromosomes were isolated from 49,XXXXY cells, stained with 33258 Hoechst $(4 \mu \mathrm{g} / \mathrm{ml})$ and chromomycin $A_{3}(40 \mu \mathrm{g} / \mathrm{ml})$, and sorted in a FACS IV, equipped with two argon ion lasers. The arrow points to the contour lines localizing chromosome 21 . Contour lines are at $60,70,90,100,120,140$, and 160 chromosomes per unit

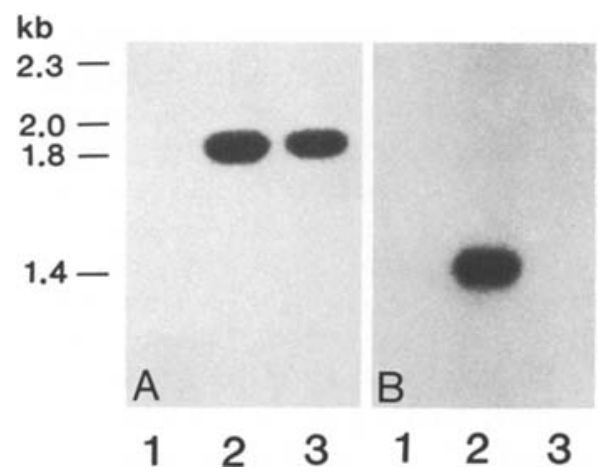

Fig. 2A, B. Localization of DNA fragments to human chromosome 21. Radiolabeled human DNA inserts cloned in piAN7 were hybridized (Southern 1975) to HindIII-digested DNA from (lane 1) mouse A9 cells, (lane 2) MD11 (46,XX cells), and (lane 3) WA17, an A9human somatic cell hybrid containing 2-3 copies of human chromosome 21 as its sole detectable human complement (Raziuddin et al. 1984). A Hybridization to bands in lanes 2 and 3 but not lane 1 identifies homology with human chromosome 21. B Hybridization to bands in lane 2 but not lane 3 identifies clones lacking homology to chromosome 21

containing unique recognition sites for a number of restriction endonucleases, including Pst I, Eco RI, and Hind III. PiAN7 was then subcloned as a Pst I fragment into the Pst I site of a high copy number plasmid derived from pBR322, pGFY218 (J.Brosius, unpublished), obviating the requirement for plasmid p3 ordinarily used to select for the sup $\mathrm{F}$ function of piAN7 (Seed 1983). Plasmid p3 confers kanamycin resistance and carries genes for ampicillin and tetracycline resistance with amber mutations suppressible by the supF gene of piAN7. The chimeric pGFY218/piAN7 plasmid was isolated, digested with Hind III and Eco RI, and subjected to electrophoresis in a low melt agarose gel. Linearized piAN7 DNA was isolated from this gel by chromatography on RPC-V
(Schleicher and Schuell), and treated with calf intestinal alkaline phosphatase (Boehringer-Mannheim) before ligation to human DNA inserts.

Isolation of human 21-enriched chromosomes employed two-dimensional flow sorting using the dyes, chromomycin $\mathrm{A}_{3}$ and 33258 Hoechst (Calbiochem.) as described in Gray et al. (1979), Langlois et al. (1982), Sahar and Latt (1978), and Lalande et al. (1985) and illustrated in Fig. 1. A 50-ng sample of chromosome 21-enriched DNA, corresponding to nearly $3 \times 10^{6}$ chromosomes, was isolated, cleaved with the restriction enzymes Eco RI and Hind III, and ligated to $10 \mathrm{ng}$ of the phosphatase-treated piAN7 DNA. The resulting recombinant plasmids were used to transform MC1061 [p3] (Neve and Kurnit 1983; Seed 1983; Casadaban and Cohen 1980). The transformed bacteria were grown on L broth agar plates containing $50 \mu \mathrm{g} / \mathrm{ml}$ kanamycin, $50 \mu \mathrm{g} / \mathrm{ml}$ ampicillin, and $10 \mu \mathrm{g} / \mathrm{ml}$ tetracycline, yielding 10 colonies/ng of human DNA.

\section{Analysis of the repetitiveness (REP number) of human DNA inserts subcloned in piAN7}

Bacterial strains (LG75, MC1061 [p3], and LE392) were described in Neve et al. (1983). One million plaque forming units (pfu) from a large insert human genomic library cloned in the bacteriophage Charon 4A (the gift of Dr. T. Maniatis) as described by Lawn et al. (1978) were plated on MC1061 [p3] harboring a recombinant piAN7 plasmid carrying a human DNA insert to be tested. The bacteria were propagated in L broth containing $50 \mu \mathrm{g} / \mathrm{ml} \mathrm{kanamycin,} 50 \mu \mathrm{g} / \mathrm{ml}$ ampicillin, and $10 \mu \mathrm{g} / \mathrm{ml}$ tetracycline. Amber phage (Charon 4A), recombining with miniplasmids presumably via insert sequence homology (Seed 1983), will acquire the amber suppressor gene (of the miniplasmid). Such phage can then be detected by parallel titering on bacterial hosts themselves carying or not carrying suppressor genes. Hence, following lysis and elution, the resulting phage were titered on both the $S u$ host LE392 and the $S u^{\circ}$ host LG75. The REP number was determined by assaying the number of plaques observed on LG75 per $10^{8}$ pfu on LE392. Plasmids yielding a REP number between 1 and 10 were selected for further study since they presumably harbored nonrepetitive human DNA inserts (Neve and Kurnit 1983).

\section{Radiolabeling and mapping of human DNA inserts subcloned in piAN7}

DNA from plasmid minipreps (Maniatis et al. 1982) was cleaved with Eco RI and HindIII. Following cleavage, the DNA was subjected to electrophoresis in a $0.6 \%$ low melt agarose gel in Tris-acetate buffer, and the inserts were isolated and labeled by the oligonucleotide random primer method of Feinberg and Vogelstein (1984). The radiolabeled inserts were hybridized (Southern 1975) to Hind III-digested DNA from the following sources: mouse A9 cells (Littlefield 1964), a 46,XY human male lymphobastoid cell line (MD11), and a rodent-human somatic cell hybrid, WA17, derived from A9 containing 2-3 copies of human chromosome 21 as its sole detectable human complement (Raziuddin et al. 1984). Human DNA inserts that hybridized to a single Hind III fragment present only in DNA from MD11 and WA17 cells were assigned provisionally to chromosome 21 (Fig. 2) and then localized subregionally on chromosome 21 using Hind III- 

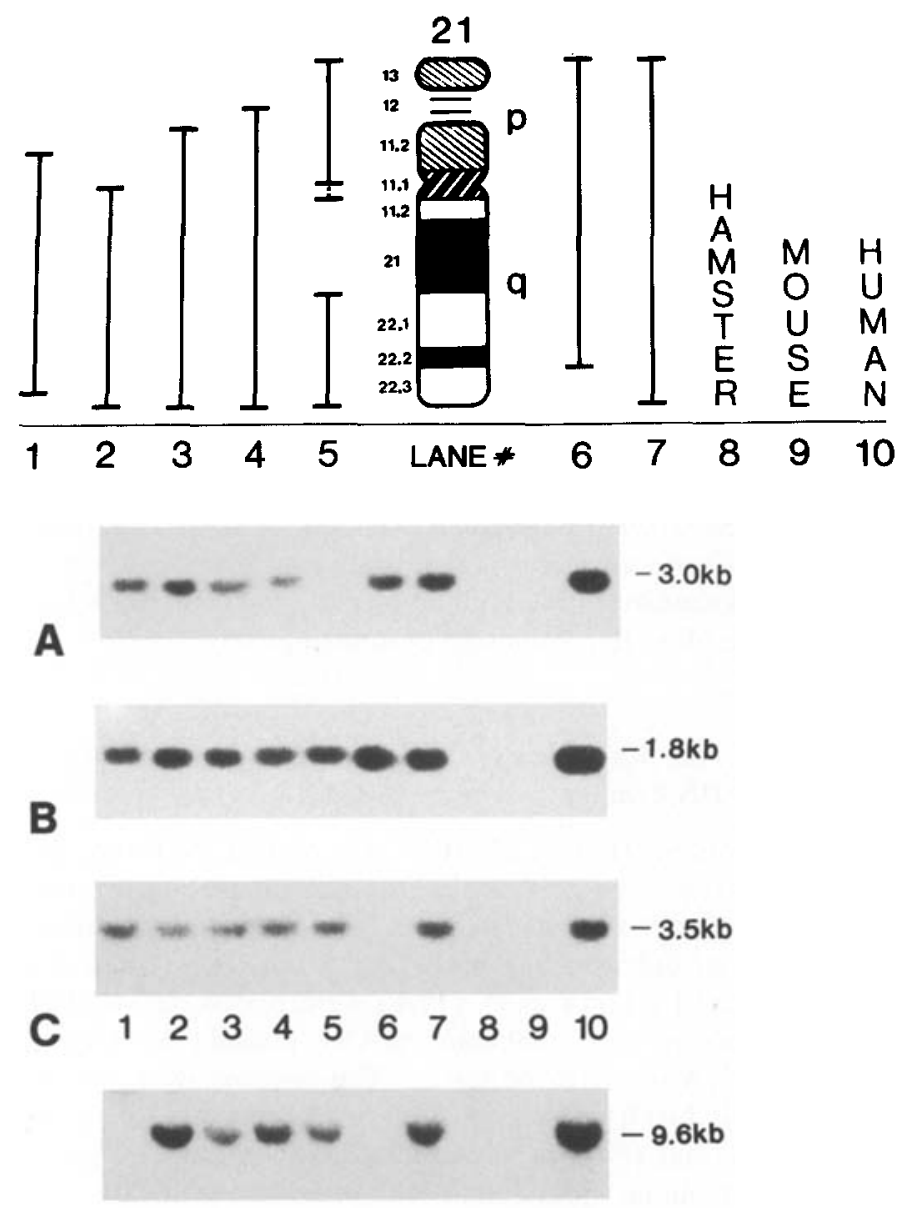

D $\quad \begin{array}{llllllllll}1 & 2 & 3 & 4 & 5 & 6 & 7 & 8 & 9 & 10\end{array}$

Fig. 3A-D. Localization of different DNA segments to four regions of the long arm of human chromosome 21 using an extended rodenthuman hybrid cell DNA panel [diagrammed at the top; (Van Keuren et al. 1986)]. Lane 1 R2-10, Chinese hamster ovary (CHO) somatic cell hybrid containing a human ring chromosome 21 resulting in deletion of the distal tips of both the long and short arms of chromosome 21. Lane $22 \mathrm{Fu}^{\mathrm{r}} 1$, a CHO hybrid containing $21 \mathrm{q}$ translocated to a $\mathrm{CHO}$ chromosome; the centromere appears to contain hamster DNA. Lane 3 153E7BX, CHO hybrid with a human chromosome 21 with the indicated deletion extending from just below the ribosomal stalks to 21 pter. Lane $472532 \mathrm{X}-6$, CHO hybrid with a human chromosome 21 with a breakpoint in the ribosomal locus, resulting in a deletion of the short arm above the ribosomal DNA stalks (M.Van Keuren, unpublished data). Lane 5 ACEM2-90, CHO hybrid containing a rearranged chromosome 21 characterized by a complex rearrangement yielding a chromosome with duplications of some parts of chromosome 21 and deficiencies of other regions of this chromosome (Bradley et al. 1986): several DNA probes known to map to the proximal part of the long arm of chromosome 21 are deleted from this chromosome (M. Van Keuren and G. Stewart, unpublished data). Lane 6 21-8Ab5-23a, a CHO hybrid containing an 8;21 translocation chromosome such that 21q22.3 is deleted (Drabkin et al. 1985). Lane 7 WA17; intact chromosome 21 in an A9 hybrid (Raziuddin et al. 1984). Lane $8 \mathrm{Ade}^{-} \mathrm{C}$, Chinese hamster cells. Lane 9 A9 mouse cells (Littlefield 1964). Lane 10 human placental DNA. Radiolabeled chromosome 21 DNA probes hybridized to Hind III-digested DNA: A probe B79: $21 \mathrm{q} 11.1 \rightarrow 21 \mathrm{q} 21 ; \mathbf{B}$ probe B15: $21 \mathrm{q} 21 \rightarrow 21 \mathrm{q} 22.2 ; \mathbf{C}$ probe D3: proximal 21q22.3, and $\mathbf{D}$ probe B88: distal 21q22.3

digested DNA from the somatic hybrid cell (Van Keuren et al. 1986) mapping panel described in Fig. 3. Each hybrid contained, with few exceptions (see legend to Fig. 3), part of chromosome 21 as its sole detectable human complement.

\section{Results}

\section{The REP assay for few-copy DNA sequences}

The REP assay is based on the assumption that the representation of a given DNA sequence in genomic libraries correlates with the frequency of representation of that sequence, i.e., sequence repetitiveness, in the genome. In turn, the frequency of representation of the given DNA sequence in a genomic library should correlate with the frequency of successful recombination between the given DNA sequence subcloned in piAN7 and a human genomic recombinant library. We have demonstrated (Neve and Kurnit 1983) that the determination of the REP number for a human DNA sequence subcloned in piAN7 indeed represents a useful and rapid approximation of the repetitiveness of that sequence in the human genome. In particular, we found that sequences with REP numbers (Materials and methods) below 10 are "fewcopy," i.e., they hybridize to genomic DNA fragments that may be assigned to individual human chromosomes (Neve and Kurnit 1983).

The REP number was determined for each of the 400 bacterial colonies containing an insert cloned into piAN7; 77 manifested REP numbers between 1 and 9. Plasmid minipreps from these 77 plasmids yielded 92 Hind III-Eco RI DNA inserts. Of these inserts 49 could be mapped on Southern blots. Of the remainder, 2 were too repetitive for mapping purposes, 6 were too small, 4 were unstable and deleted during further propagation, and 31 did not yield sufficient signal to permit mapping, perhaps because they contained small, poorly labeling inserts. Of the 49 inserts that could be mapped 28 did indeed hybridize to human genomic DNA fragments on chromosome 21, i.e., these genomic DNA fragments were present in human (MD11) and mouse plus human chromosome 21 somatic cell hybrid (WA17) DNAs, but were absent from mouse (A9) DNA (Fig. 2A). Of these 28 inserts 10 hybridized as well to other human genomic DNA fragments not present on chromosome 21 , as other fragments were present in MD11 $(46, \mathrm{XY})$ DNA but not in WA17 (mouse plus human chromosome 21) DNA. One of the 28 inserts (probe B88) also cross-hybridized to mouse DNA, making it a likely candidate for expressed genomic sequences (Kunkel et al. 1983). Of the 49 inserts 21 were not chromosome 21 specific. An example of this is shown in Fig. 2B. This probe hybridized to MD11 DNA $(46, \mathrm{XY})$ but not to WA17 DNA (mouse plus human chromosome 21).

Each of the DNA inserts that mapped to chromosome 21 was localized subregionally on chromosome 21 using a somatic cell mapping panel described by Van Keuren et al. (1986). As shown in Fig. 3, nonrepetitive DNA fragments from chromosome 21 have been isolated from all four subregions of $21 \mathrm{q}$ that may be distinguished using this panel. The assignment of the 26 clones that mapped to $21 \mathrm{q}$ is shown in Table 1.

In contrast, E79 and C65, the two probes with a REP number between 1 and 9 that mapped to the short arm of chromosome 21 , showed a simple hybridization pattern as expected from the low REP number but mapped to other human chromosomes as evidenced by the more intense hybridization to total human DNA compared to WA17 DNA (shown in Fig. 4 for probe $\mathrm{C} 65$ ). These two probes map to the distal portion of $21 \mathrm{p}, 21 \mathrm{p} 12 \rightarrow 21 \mathrm{pter}$. The absence of single copy DNA fragments from the short-arm region of chromosome 21 is striking and is consistent with the results of Van Keuren et al. 
Table 1. Localization of chromosome 21 probes. DNA in lanes 1 through 10 are the same as in Fig. 3. Insert sizes in kilobase pairs (kb) are determined from Eco RI, Hind III double digests. Genomic sizes are derived from Hind III digests

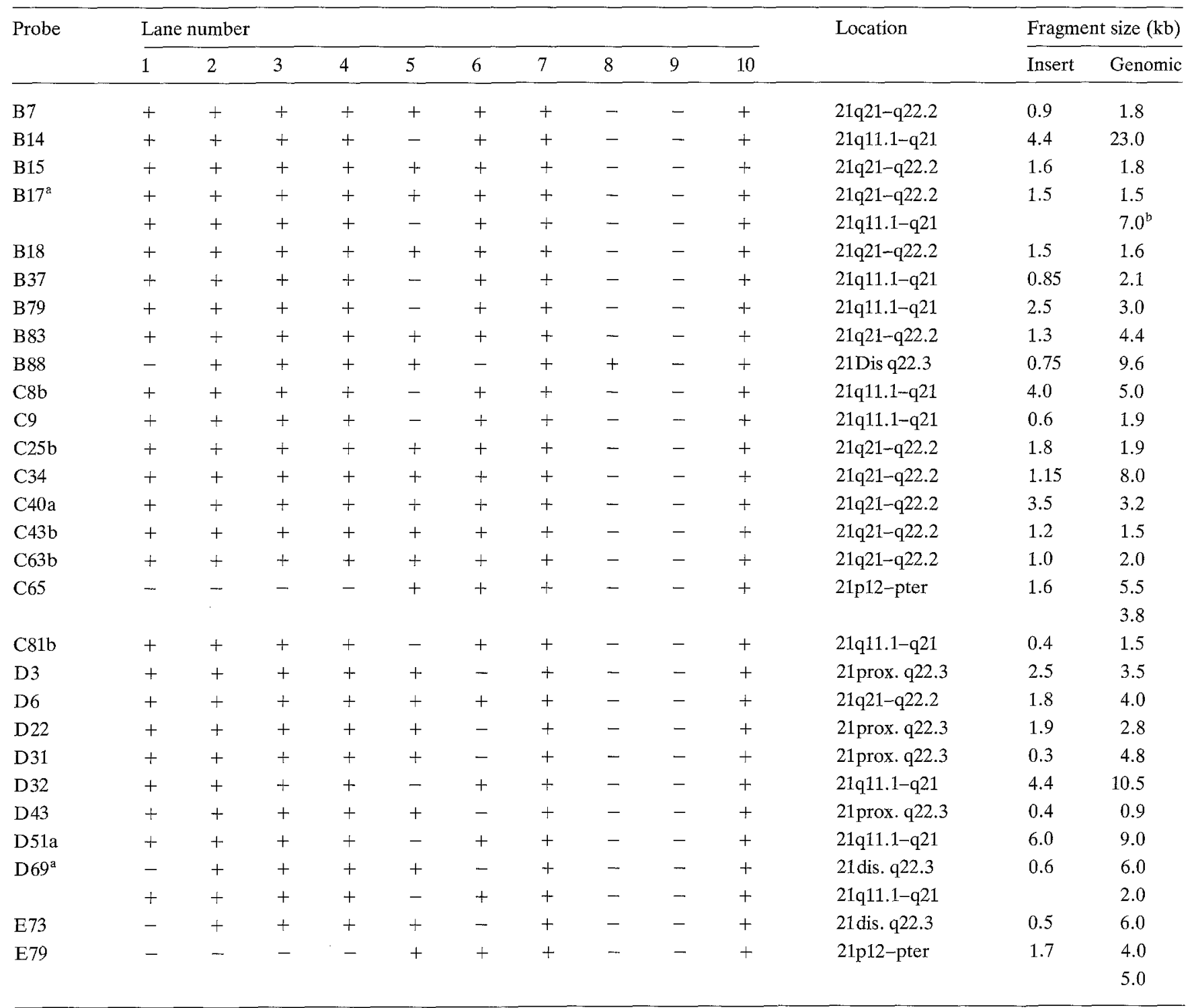

a Probes show homology to different regions of $21 \mathrm{q}$

b Weak hybridization

(1986), who subregionally mapped 30 probes with the mapping panel in Fig. 3. Van Keuren et al. (1986) found that all three probes that mapped to $21 p$ were not single copy, as they recognized DNA sequences on multiple human chromosomes.

\section{Detecting probes mapping solely to chromosome 21}

Our recombination-based assay and subregional mapping selected DNA fragments that were present on chromosome 21, but did not eliminate DNA fragments that were also homologous with DNA sequences on other chromosomes. For specific purposes, it might prove desirable to identify DNA fragments that recognize sequences on multiple human chromosomes. Figures 5 and 6 illustrate a rapid initial approach for accomplishing this. Probe B14 recognized a single band that maps to human chromosome 21 and a generalized smear presumably resulting from hybridization to low-order repetitive DNA sequences present on multiple chromosomes (Fig. 5A); probe B15 recognized a single band that maps to human chromosome 21 (Fig. 5B). Metaphase chromosomes were flow sorted into five fractions spanning the karyotype (fractions A-F) directly onto nitrocellulose filters (Lebo et al. 1984; Collard et al. 1985). The first fraction corresponded to the chromosome 21 peak, obtained by bivariate flow cytometric analysis (Fig.1). Probe B15 hybridized strongly only to the chromosome 21 fraction in Fig. 6, demonstrating that this probe detected only sequences on chromosome 21 . In contrast, B14 hybridized strongly to all six fractions, in agreement with the smear patttern seen on Southern blotting. Work in progress (G.Stewart and R. Tanzi, unpublished data), using our probes to identify restriction length fragment polymorphisms segregating in pedigrees in a Mendelian fashion, further identifies the chromosome 21 specificity of the single copy probes. 


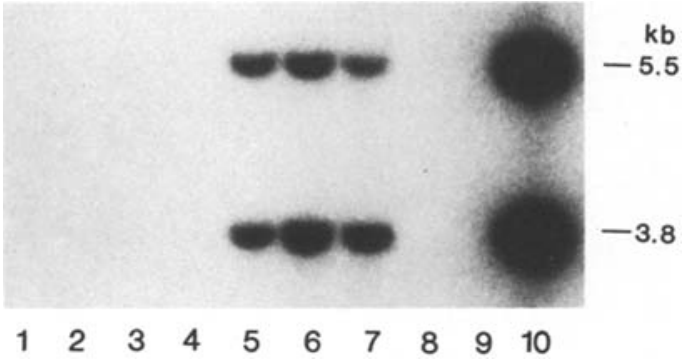

Fig. 4. Mapping of probe $\mathrm{C} 65$ to $21 \mathrm{p} 12 \rightarrow 21$-pter. DNA samples in the lanes of the blot are the same as those in Fig. 3. Note in particular the restriction of signal to those hybrids (lanes $5,6,7$ ) containing the short arm of 21 and the absence of hybridization to DNA (lanes 3,4) containing only that portion of $21 \mathrm{p}$ at or proximal to band $21 \mathrm{p} 12$. The unusually intense signal in lane 10 (human DNA) is, as mentioned in the text, compatible with the existence of sequences homologous to probe C65 elsewhere in the genome than just chromosome 21

$23 \mathrm{~kb}$

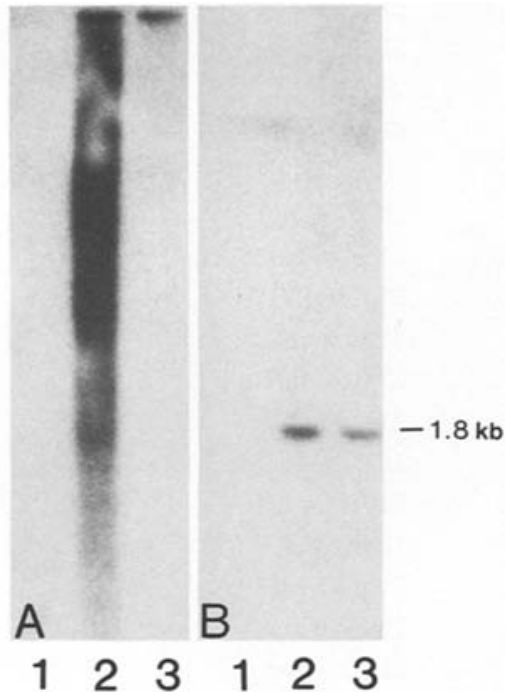

Fig. 5A, B. Hybridization of probes B14 (A) and B15 (B) to the chromosome mapping panel of Fig. 2. Note the smear in lane 2 of $(\mathbf{A})$ in contrast to the single band at $1.8 \mathrm{~kb}$ seen in $(\mathbf{B})$

\section{Discussion}

\section{Specificity of the REP assay}

These results are consistent with our previous report that the REP assay discriminates few-copy from low-order repetitive DNA sequences (Neve and Kurnit 1983). Out of 92 inserts isolated with REP numbers between 1 and 9 , only 2 were too repetitive to permit assignment of distinct bands to specific chromosomes. These 2 repetitive DNA inserts hybridized to discrete bands in the human chromosome 21 lane, but detected too many additional bands in the total human genomic DNA lane to permit the assignment of discrete bands to individual human chromosomes. Given the highly stringent requirement for sequence matching that characterizes the recombinationbased assay (Neve and Kurnit 1983; Seed 1983; Neve et al. 1983), these repetitive DNA sequences on chromosome 21 must recombine infrequently, in the miniplasmid-phage coinfection, with their cognates on other human chromosomes, presumably due to divergence from the chromosome 21 -specific DNA sequences cloned in piAN7.

\section{Specificity and rapidity of the merged flow sorting and REP assays}

Our recombination-based screen utilized $50 \mathrm{ng}$ of DNA from three million chromosome 21 particles. This generated approximately ten colonies per ng of flow-sorted DNA. Following determination of the sequence repetitiveness of the flowsorted DNA inserts using the REP assay, approximately $10 \%$ exhibited REP numbers between 1 and 9, indicating the presence of few-copy human DNA inserts. More than $50 \%$ of human DNA inserts screened for in this manner (28 of 49) detected genomic DNA fragments on chromosome 21. Nonchromosome 21 DNA may in part reflect contamination from other chromosomes at levels below the cutoff (60 chromosomes per unit channel) used in Fig. 1 (see legend to Fig. 1) as well as collection of stray particles during instrument deadtime. Two of the chromosome 21 probes, B17 and D69, recognized two different size fragments on Southern blots, with each fragment mapping to a different region of the long arm of chromosome 21 . The most likely explanation for this last observation is that these sequences have homology to two different regions of $21 \mathrm{q}$.

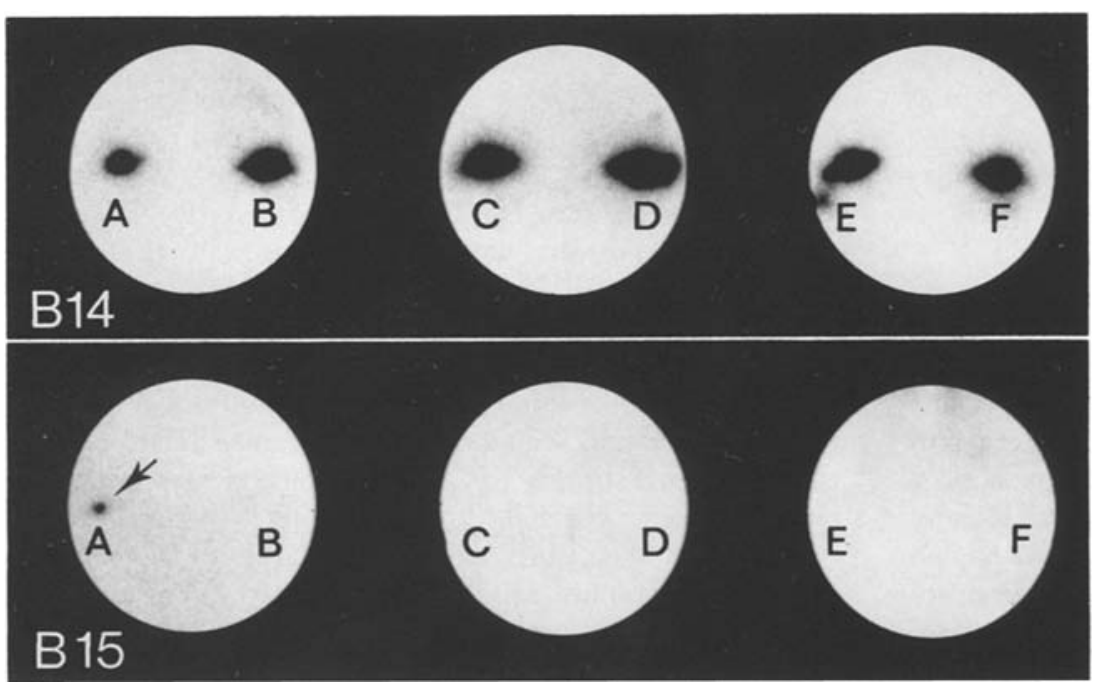

Fig. 6. Hybridization of probes B14 (top) and B15 (bottom) to dot blots of flow-sorted chromosomes. Chromosomes were sorted to contain approximately 25,000 per individual chromosome. The dots were sorted from regions of a two-dimensional histogram such as shown in Fig. 1 corresponding to chromosomes: $A(21) ; B(18,19,20,22) ; C(13,14$, $15,16,17) ; D(8,9,10,11,12, \mathrm{X}) ; E(3,4,5,6,7)$; $F(1,2)$. Note the hybridization of probe $\mathrm{B} 14$ to all dots, whereas probe B15 hybridizes strongly only to peak 21 (arrowed), which is enriched for human chromosome 21 . Neither probe B14 nor probe B15 hybridized to Y DNA (data not shown) 


\section{Generating probes for chromosome walking}

DNA sequences on chromosome 21 isolated by this assay are particularly well-suited for chromosome walking using the recombination-based methodology of Seed (1983) since the DNA inserts are already subcloned in piAN7. Indeed, the performance of the analytical REP assay is itself the first chromosome walking step. In the REP assay, the phage that plate on the $S u^{\circ}$ host LG75 contain DNA inserts, with an average size of $15 \mathrm{~kb}$ (kilobase pair) genomic DNA, that share homology with the chromosome 21 DNA insert cloned in piAN7. Bacteriophage with a DNA probe inserted in piAN7 can be isolated, random fragments of phage insert subcloned into piAN7, and the REP assay cycle reiterated. This protocol has facilitated the rapid analysis of the organization of DNA sequences in the pericentromeric region of chromosome 21 (Kurnit et al. 1984, 1986; and our unpublished data).

\section{Molecular organization of chromosome 21}

We found that 28 of 49 few-copy DNA probes detected by the REP assay mapped to chromosome 21 , and that the two shortarm probes with a low REP number localized to multiple human chromosomes. Van Keuren et al. (1986) found that 27 of 30 few-copy DNA probes on chromosome 21 mapped to the long arm, and that all three DNA sequences that localized to $21 p$ were present on other chromosomes as well. Thus, in addition to highly repeated simple sequence DNAs (Gosden et al. 1975) and moderately repeated ribosomal DNA sequences present on 21p that are known to be shared among the acrocentric chromosomes (Henderson et al. 1972), even the low-order repetitive DNA sequences on $21 \mathrm{p}$ isolated to date localize to multiple chromosomes. This argues that the recombination events that resulted in the distribution of ribosomal and satellite DNA sequences to the short arms of acrocentric chromosomes during higher primate evolution involved the entire short arm. These findings also suggest that it may not be possible to obtain single copy DNA fragments that map uniquely to chromosome $21 \mathrm{p}$ in all humans, consistent with the finding that exchanges between human acrocentric short arms occur frequently enough to be observable in vitro (Nielsen et al. 1974; Therman et al. 1981; Livingston et al. 1985).

Acknowledgernents. This research was supported by grants from the NIH (HD18658 to G.D.S., S.R., D.M.K., M.L., and S.A.L.; HD20118 to D.M.K.; HD17449, HD06470, and CA01017 to D.P., M.V., and H.D.); a grant from the American Heart Association (Massachussetts Division) to D.M.K. (K04 HD00687); a March of Dimes Clinical Research Grant to D.M.K., and by a contract from Becton Dickinson and Company (S.A.L., U.T., and G.M.). We thank A.Flint for assistance with chromosome sorting and P. Harris for advice on chromosome dot blots. D.M.K. and S.A.L. are investigators of the Howard Hughes Medical Institute.

\section{References}

Bradley CM, Patterson D, Robinson A (1986) Somatic cell genetic studies on a family with Down syndrome due to an unusual translocation (21q22 $\rightarrow 21$ qter). Trisomy $21: 41-52$

Casadaban MJ, Cohen SN (1980) Analysis of gene control signals by DNA fusion and cloning in Escherichia coli. J Mol Biol 138:179207

Collard JG, Boer PAJ de, Janssen JWG, Schijven JF, Jong B de (1985) Gene mapping by chromosome spot hybridization. Cytometry $61: 179-185$
Davies KE, Young BD, Elles RG, Hill ME, Williamson R (1981) Cloning of a representative genomic library of the human X chromosome after sorting by flow cytometry. Nature 293:374-376

Donlon TA, Lalande M, Wyman A, Bruns G, Latt SA (1986) Isolation of molecular probes associated with the chromosome 15 instability in the Prader-Willi syndrome. Proc Natl Acad Sci USA 83: $4408-4412$

Drabkin HA, Diaz M, Bradley CM, Le Beau MM, Rowley JD, Patterson D (1985) Isolation and analysis of the $21 q+$ chromosome in the acute myelogenous leukemia 8;21 translocation: evidence that c-mos is not translocated. Proc Natl Acad Sci USA 82:464-468

Feinberg AP, Vogelstein B (1984) A technique for radiolabeling DNA restriction endonuclease fragments to high specific activity. Anal Biochem 132:6-13

Gosden JR, Mitchell AR, Buckland RA, Clayton RP, Evans HJ (1975) The location of four human satellite DNAs on human chromosomes. Exp Cell Res 92:148-158

Gray JW, Langlois RG, Carrano AV, Burkhart-Schultz K, Van Dilla MA (1979) One and two parameter flow cytometry. Chromosoma $73: 9-27$

Gusella JF, Keys C, Varsanyi-Breiner A, Kao F-T, Jones C, Puck TT, Housman D (1980) Isolation and localization of DNA segments from specific human chromosomes. Proc Natl Acad Sci USA 77: 2829-2833

Henderson AS, Warburton D, Atwood KC (1972) Location of ribosomal DNA in the human chromosome complement. Proc Natl Acad Sci USA 69:3394-3398

Huang HV, Little PFR, Seed B (1987) Improved suppression tRNA cloning vectors and plasmid-phage recombination. In: Rodriguez $R$, Denhardt $D$ (eds) Vectors, a survey of molecular cloning vectors and their uses. Butterworths, Boston, pp 269-283

Kunkel LM, Tantravahi U, Kurnit DM, Eisenhard M, Bruns GP, Latt SA (1983) Identification and isolation of transcribed human $\mathrm{X}$ chromosome DNA sequences. Nucleic Acids Res 11 :7961-7979

Kurnit DM, Wentworth BM, De Long L, Villa-Komaroff L (1982) Construction of cloned libraries from RNA of human fetal tissues. Cytogenet Cell Genet 34:193-203

Kurnit DM, Neve RL, Morton CC, Bruns GAP, Ma NSF, Cox DR, Klinger HP (1984) Recent evolution of DNA sequence homology in the pericentromeric regions of human acrocentric chromosomes. Cytogenet Cell Genet 38:99-105

Kurnit DM, Roy S, Stewart GD, Schwedock J, Neve RL, Bruns GAP, Van Keuren ML, Patterson D (1986) The 724 family of DNA sequences is interspersed about the pericentromeric regions of human acrocentric chromosomes. Cytogenet Cell Genet 43: $109-116$

Lalande M, Schreck RR, Hoffman R, Latt SA (1985) Identification of inverted duplicated \#15 chromosomes using bivariate flow cytometric analysis. Cytometry $6: 1-6$

Langlois RG, Yu LC, Gray JW, Carrano AV (1982) Quantitative karyotyping of human chromosomes by dual beam flow cytometry. Proc Natl Acad Sci USA 79:7876-7880

Latt SA, Lalande M, Kunkel LM, Schreck R, Tantravahi U (1985) Applications of fluorescence spectroscopy to molecular cytogenetics. Biopolymers 24:77-95

Lawn RM, Fritsch EH, Parker RC, Blake GO, Maniatis T (1978) The isolation and characterization of linked delta- and beta-globin genes from a cloned library of human DNA. Cell 15:1157-1174

Lebo RV, Gorin F, Fletterick AJ, Kao FT, Cheung MC, Bruce BD, Kan YW (1984) High resolution chromosome sorting and DNA spot-blot analysis assign McArdle's syndrome to chromosome 11. Science 255:57-59

Littlefield JW (1964) Selection of hybrids from matings of fibroblasts in vitro and their presumed recombinant. Science 145:709-710

Livingston GK, Lockey JE, Witt KS, Rogers SW (1985) An unstable giant satellite associated with chromosomes 21 and 22 in the same individual. Am J Hum Genet 37:553-560

Maniatis T, Fritsch EF, Sambrook J (eds) (1982) Molecular cloning: a laboratory manual. Cold Spring Harbor Laboratory, Cold Spring Harbor, NY

Muller U, Lalande M, Donlon T, Latt SA (1986) Moderately repeated DNA sequences specific for the short arm of the human $Y$ 
chromosome are present in $\mathrm{XX}$ males and reduced in copy number in an XY female. Nucleic Acids Res 14:1325-1340

Neve R, Kurnit DM (1983) Comparison of sequence repetitiveness of human cDNA and genomic DNA using the miniplasmid vector, piVX. Gene 23:355-367

Neve RL, Bruns GAP, Dryja TP, Kurnit DM (1983) Retrieval of human DNA from rodent-human genomic libraries by a recombination process. Gene $23: 343-354$

Nielsen J, Friedrich U, Hreidarsson AB, Noel B, Quack B, Mottet J (1974) Brilliantly fluorescing enlarged short arms D or G. Lancet I: $1049-1050$

Raziuddin A, Sarkar FH, Dutkowski R, Shulman L, Ruddle FH, Gupta SL (1984) Receptors for human alpha and beta interferon but not for gamma interferon are specified by human chromosme 21. Proc Natl Acad Sci USA 81:5504-5508

Sahar E, Latt SA (1978) Enhancement of banding patterns in human metaphase chromosomes by energy transfer. Proc Natl Acad Sci USA 75:5650-5654

Seed B (1983) Purification of genomic sequences from bacteriophage libraries by recombination and selection in vivo. Nucleic Acids Res 11:2427-2445

Southern EM (1975) Detection of specific sequences among DNA fragments separated by gel electrophoresis. J Mol Biol 98:503517
Therman E, Otto PG, Shahidi NT (1981) Mitotic recombination and segregation of satellites in Bloom's syndrome. Chromosoma 82: 627-636

Van Dilla MA, Deaven LL, Albright KL, Allen NA, Aubuchon MR, Bartholdi MF, Brown NC, Campbell EW, Carrano AV, Clark LM, Cram LS, Crawford BD, Fuscoe JC, Gray JW, Hildebrand CE, Jackson PJ, Jett JH, Longmire JL, Lozes CR, Luedemann ML, Martin JC, McNinch JS, Meincke LJ, Mendelsohn ML, Meyne J, Moyzis RK, Munk AC, Perlman J, Peters DC, Silva AJ, Trask BJ (1986) Human chromosome-specific DNA libraries: construction and availability. Bio/Technology 4:537-552

Van Keuren ML, Watkins PC, Drabkin HA, Jabs EW, Gusella JF, Patterson D (1986) Regional localization of DNA sequences on chromosome 21 using somatic cell hybrids. Am J Hum Genet 38: 793-804

Young BD (1984) Chromosome analysis by flow cytometry. A review. Basic Appl Histochem 28:9-19

Received December 3, 1987 / Revised February 10, 1988 